\title{
A prospective study of psychomotor performance of driving among two kinds of shift work in Iran
}

Soheil Saadat ${ }^{1}$, Mojgan Karbakhsh ${ }^{2}$, Mahnaz Saremi $^{3}$, Iraj Alimohammadi ${ }^{4}$, Hassan Ashayeri ${ }^{5}$, Mahsa Fayaz $^{6}$, Farideh Sadeghian ${ }^{7}$, Reza Rostami ${ }^{8}$

${ }^{1} \mathrm{MD}, \mathrm{PhD}$, Associate Professor of Epidemiology, Sina Trauma and Surgery Research Center, Tehran University of Medical Sciences (TUMS), Tehran, Iran

${ }^{2} \mathrm{MD}, \mathrm{PhD}$ of Community Medicine, Associate Professor of Community Medicine, Department of Community Medicine, School of Medicine, Tehran University of Medical Sciences (TUMS), Tehran, Iran

${ }^{3} \mathrm{PhD}$ of Ergonomics, Associate Professor, School of Health, Safety and Environment, Shahid Beheshti University of Medical Sciences, Tehran, Iran

${ }^{4} \mathrm{PhD}$ of Occupational Health, Associate Professor of Occupational Health, Department of Occupational Health Engineering, School of Public Health, Iran University of Medical Sciences, Tehran, Iran

${ }^{5} \mathrm{MD}$, PhD, Professor of Neurology and Psychiatry, Department of Basic Sciences in Rehabilitation, School of Rehabilitation Sciences, Iran University of Medical Sciences, Tehran, Iran

${ }^{6}$ MSc of Biostatistics, Department of Epidemiology and Biostatistics, School of Public Health, Shahroud University of Medical Sciences, Shahroud, Iran

${ }^{7} \mathrm{PhD}$ Candidate, Sina Trauma and Surgery Research Center, Tehran University of Medical Sciences (TUMS), Tehran, Iran

${ }^{8}$ Psychiatrist, Associate Professor, Department of Psychology, Faculty of Psychology and Educational Science, University of Tehran, Tehran, Iran

Type of article: Original

\begin{abstract}
Background and aim: Driving after a night shift imposes a risk on health care professionals and other road users. The aim of this study was to measure psychomotor performance of driving of night shift nurses compared to day-shift nurses.

Methods: Forty-seven volunteer female nurses working at Sina hospital in Tehran, Iran, with a call in all departments of hospital, participated in this study (23 night shift and 24 day shift nurses) in 2016. The tests included RT for simple reaction time, ATAVT for perceptual speed, LVT for visual orientation and ZBA for time anticipation. Data collection tools were individual characteristics, 11-item circadian type inventory (CTI), Stanford sleepiness scale (SSS), and Swedish occupational fatigue inventory (SOFI-20) questionnaires. Psychomotor driving performance was assessed using validated computerized traffic psychological battery of Vienna Test System (VTS), before and after the shifts. Data analysis was performed using paired-samples t-test and Linear Regression.

Results: The mean age of day and night-shift nurses were $31.4 \pm 5.6$ and $28.7 \pm 3.9$ years respectively, no significant difference between two groups. Thirty percent of night shift and $16.7 \%$ of day shift nurses reported traffic accidents in the past year. The results revealed that, scores based on viewing times in visual orientation test $(\mathrm{p}=0.005)$, and median reaction time score in choice reaction time and reactive stress tolerance test $(\mathrm{p}=0.045)$, had a significant association with a 12 -hour night shift with a 3-hour nap.

Conclusions: Twelve-hour night shift work impairs choice reaction time and visual orientation in nurses, even though they take a 3- hour nap during the shift. These skills are required for safe driving.

Keywords: Psychomotor test, Driving ability, Night shift, Nurse, Reaction time test

\section{Corresponding author:}

Farideh Sadeghian, Sina Trauma and Surgery Research Center, Tehran University of Medical Sciences (TUMS), Tehran, Iran.

Tel:+98.2166757001-5, Fax: +98.2166757009, Postal Code: 1136746911, Email: farsadeghian@gmail.com

Received: October 10, 2017, Accepted: December 17, 2017, Published: February 2018

iThenticate screening: December 11, 2017, English editing: February 03, 2018, Quality control: February 15, 2018

This article has been reviewed / commented by six experts

(C) 2018 The Authors. This is an open access article under the terms of the Creative Commons Attribution-NonCommercialNoDerivs License, which permits use and distribution in any medium, provided the original work is properly cited, the use is non-commercial and no modifications or adaptations are made.
\end{abstract}




\section{Introduction}

Mortality rate from traffic accidents are a main health problem globally (1). Fatigue and sleepiness cause $10 \%$ to $30 \%$ of fatal traffic deaths (2). One of the most common causes of short sleep while driving, is the lack of sleep due to job demands (3). Night shift workers are at particular risk of road traffic collisions while commuting home due to sleepiness (4). Sleepiness reaches its maximum level at the end of the night shift (5). Nurses, particularly those who work 12-hour night shifts, are at risk of road traffic collisions while driving home after their shift due to drowsy driving, and a large number of nurses have reported difficulty in staying awake while driving home (6). A study of nurses driving home after a night shift revealed that the maximum total blink duration increased, which is linked to an increased incidence of sleep-related episodes such as reporting falling asleep at the stop light (7). In one study on 45 nurses, who worked 12-hour night shifts in a critical care unit, 95\% reported at least 1 road traffic collision or near accident while driving to and from the hospital during the past year (8). Moreover, another study on nurses working night shifts found impaired performance, lowered consciousness, evidence of sleep-wake disorder, and involuntary sleep at work, or while driving home (6). A study conducted on night and day shift workers in Norway measured objective sleepiness with a simple serial reaction time test. Results revealed a significant reduction in reaction time across days for the night shift workers, but not for the day shift workers (9). In another study, an increased occurrence of eye blinks and longer braking reaction time were observed among sleepy drivers (10). Several researches have examined the psychomotor skill changes associated with sleepiness. Lee ML et al. compared driving performance and physiological signs of sleepiness after night shift with after-sleep driving and found a significant increase in several psychomotor measures including the number of path outings, driving with the emergency brake, slow eye movement, increased blink period, micro sleep periods, and time with eyes closed (11). Akerstedt et al. demonstrated that night shift tests on driving simulators indicated increased electroencephalographic (EEG) alpha and theta actions (12). One study indicated that drowsiness impairs performance of driver to a degree comparable to alcohol consumption (13). Driving is a complex task that requires adequate cognitive, visual, and motor skills. The driver must have sufficient speed, attention, and visual perceptual skills. Drivers should also have the ability to process several environmental signals simultaneously so that they can react and make decisions rapidly and accurately (14). Some studies have found improvement in cognitive and driving performance of the shift workers after napping $(15,16)$. Occupational interventions to save lives need to determine which specific psychomotor skills needed for driving are most severely affected by night shift work. The aim of this study was to measure psychomotor performance of driving of night shift nurses compared to day shift nurses.

\section{Material and Methods \\ 2.1. Participants}

In the present study, 50 nurses ( 25 day shift nurses and 25 night shift nurses) were included, but 3 nurses withdrew after the training session. The sample size was estimated on the basis of previous study using sample size formula by STATA 12. In a previous study the mean reaction time of study participants was 349 milliseconds. The estimated sample size to detect a $15 \%$ change in the reaction time with a power of $80 \%$ by using paired-samples t-test was 21 . Therefore, this study was conducted on 47 female nurses (23 night shift nurses and 24 day shift nurses), who worked at Sina hospital, in Tehran (Iran) in 2016. In Sina hospital, the day shift was 7 hours (7:00 AM-2:00 PM), and the night shift was 12 hours (7:00 PM-7:00 AM), with a 3-hour nap time (00.00-03.00 AM or 003:01-06:00 AM) for the nurses. The nurses chose their own nap time. In this study day shift nurses usually work on the day shift and night shift nurses usually work on the night shift.

\subsection{Selection Criteria}

For homogeneity of the participants of the study, and because male nurses always work more than one shift in 24 hours, only healthy female nurses were included in our study. Those aged from 20 to 40 years, and had at least 1 year job experience and a driver's license, were actively driving, and worked only 1 shift during the past 24 hours of the study were included. They were asked not to drink coffee or take sleeping or anti-sleep pills 24 hours before the trial. The exclusion criteria were people who use medication for sleeping or sleep disorders.

\subsection{Data Collection Procedures}

This study was conducted at the laboratory of Sina Trauma and Surgery Research Center located at Sina hospital. This is a public and specialized hospital with 23 departments and 477 beds. Volunteer nurses from the night shift and day shift program of the hospital participated in the study with a call in all departments of Sina Hospital. They were recruited based on the inclusion criteria and were provided with a full explanation of the study and research purposes. We used the VTS to study the fitness to drive. Various studies conducted on traffic psychological evaluation used VTS standardized tests to determine the fitness to drive $(17,18)$. In several countries including 
Germany and Austria, drivers who have lost their privilege to drive in cases of serious traffic violations, are required by law to pass these tests to regain their driver's license (19). The VTS tests were performed over 3 sessions for them. All the participants attended a training session (the first session). After ensuring that the nurses were fully trained, we included them in the study. They were asked to take the computerized tests before starting their shift, i.e., at 7:00 AM for those working on the day shift and at 7:00 PM for those working on the night shift (second session). Then, they were asked to take the tests again at the end of the same shift, i.e., at 2:00 PM for those on the day shift and at 7:00 AM for those on the night shift (third session) (Figure 1).

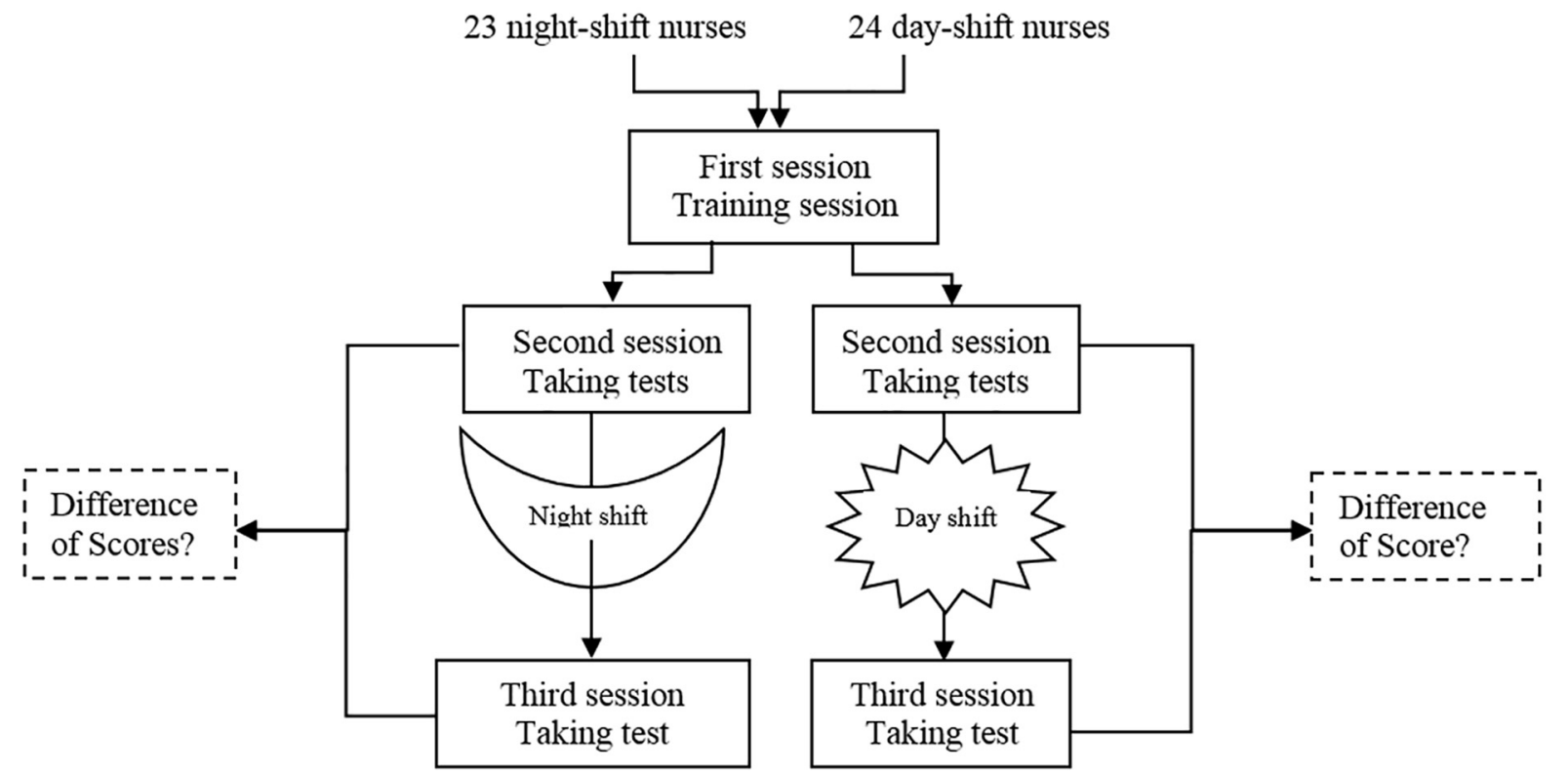

Figure 1. Study diagram

\subsection{Ethical Aspects}

To motivate the participants to present their best performance, it was announced that they would be awarded a maximum cash bonus of $\$ 14$ according to the score achieved in the sessions. All the participants signed an informed written consent form. The research project was approved by the Research Ethics Committee of Tehran University of Medical Sciences (IR TUMS.REC.2015.1984-7/12/2015) and in accordance with the ethical guidelines of the 1975 Declaration of Helsinki.

\subsection{Data Collection Tools}

Data collection tools included validated computerized traffic psychological battery of VTS, whose validity and reliability have been proven in previous studies $(19,20)$, and 4 questionnaires. The questionnaires were an individual characteristics questionnaire. Moreover, the 11-item Circadian Type Inventory (CTI) (21), Stanford Sleepiness Scale (SSS) (22), and Swedish Occupational Fatigue Inventory (SOFI-20) questionnaires (23) were used. The validity and reliability of these tools have been reported in other studies (21-23). The CTI questionnaire measures rhythm, stability, and amplitude of circadian rhythm. Flexible/Rigid (FR) deliberates a sign of rhythm stability and expresses flexibility or rigidity of sleeping habits. Rigid types refer to those who are less able to sleep at unusual hours. Languid/vigorous (LV) denotes the amplitude of circadian. Languid types have problems to overcome sleepiness. Vigorous types are more alert during the day, require less sleep, and are less influenced by sleep inertia on waking than languid types. Vigorous and flexible types would best deal with shift work (24). A traffic psychological test battery of VTS assessments was used to collect the psychomotor performance data. Each test has different forms in this battery, and we selected the tests by consulting a relevant expert. In our study, 4 tests were used as follows (19): Adaptive Tachistoscopic Traffic Perception Test (ATAVT) (S1 form): In this test, pictures of traffic sights are offered to the participants for 1 second. Then, they have to choose from a list of 5 different object classes that were observable in the picture (e.g., motor vehicles, motorcyclists, pedestrians, traffic lights, and road signs). The main variable of this test was "overview" that measures perceptual speed. High score reflects better visual observational ability and skill in obtaining an overview. The reliability of this variable was determined as Cronbach's alpha score equal to 0.8. Determination Test (DT) (S1 form): This test evaluates the 
complex choice reaction time and reactive stress tolerance, and speed under conditions of sensory stress. The main variables of this test in the present study were median reaction time, correct, incorrect, and omitted responses. A low score in omitted and incorrect response and median reaction time and a high score in correct response reflect better performance in this test. The reliability of this variable was determined as Cronbach's alpha score equal to 0.98 . Visual Pursuit Test (LVT) (S3 form): This test measures visual orientation performance, visual pursuit ability and selective attention. The main variables studied by this test were scored based on viewing times. High score reflects fast and accurate perception in orientation and visual pursuit ability. The reliability of this variable was determined as Cronbach's alpha score equal to 0.92. High score reflects the better performance. Time Movement Anticipation Test (ZBA) (S4 form): This test assesses the ability to predict the speed and movement of an object in a space. The main variable under study in this test was median deviation time. Low score reflects the better performance to anticipate the speed of objects in a space. The reliability of this variable was determined as Cronbach's alpha score equal to 0.72 .

\subsection{Statistical analysis}

Continuous variables are presented as mean \pm standard deviation (SD). The difference between scores at the beginning and the end of the shift was calculated for each participant, and the difference between the scores of the 2 groups (night shift vs. day shift) was tested using t test. Multiple linear regression analysis was used to study the effects of shift (night vs. day) on the score change (i.e. difference of the scores obtained after the shift, compared to the scores obtained before the shift). The effect of the following variables were controlled by including them in the model: age, driving experience (less or more than 5 years), history of Road Traffic Accidents (RTC) during the past year, the amount of sleep during the past 24 hours (equal, less, or more than 6 hours), circadian rhythm (flexible/rigid), amplitude (languid/vigorous), fatigue, sleepiness score, and marital status. The power of the study was calculated for each test to detect the association of the type of the shift with the improvement in the R-square of the model. For this purpose, the R-square for the model containing all variables except the shift type was calculated. Next, the amount of improvement in R-square of the model by adding the shift type (as the main independent variable) was detected. Thus, the power of the study to improve the R-square of the model by $5 \%, 10 \%$, and $15 \%$ was obtained. For this purpose, power analysis sample size software (Hintze, J. (2011) PASS 11 NCSS, LLC. Kaysville, Utah, USA. www.ncss.com) was used. Kolmogorov Smirnov test was used for evaluation of normality. When a variable did not have a normal distribution, it was transformed into a normally-distributed variable using the appropriate transformation; all tests were performed on the transformed variable. Data analysis was conducted using IBMC SPSSC Statistics version 21 (IBMC Corp., Armonk, NY, USA). The level of significance was set at p-value $\leq 0.05$.

\section{Results}

In this study, 47 nurses (23 night shift nurses and 24 day shift nurses) completed the study. Table 1 demonstrates the individual characteristics of the participants. The mean age of the study group was $30.05 \pm 4.75$ (age of day and night-shift nurses were $31.4 \pm 5.6$ and $28.7 \pm 3.9$ years respectively), with no significant difference between the two groups.

Table 1. Comparison of study groups characteristics

\begin{tabular}{|c|c|c|c|c|}
\hline \multicolumn{2}{|l|}{ Variables } & Night shift $(n=23)^{*}$ & Day shift $(n=24)^{*}$ & p-value \\
\hline \multicolumn{2}{|c|}{ Age (years) $)^{\mathrm{b}}$} & $28.7 \pm 3.9$ & $31.4 \pm 5.6$ & $0.094^{*}$ \\
\hline \multicolumn{2}{|c|}{ Driving experience (years) ${ }^{b}$} & $6.1 \pm 3.5$ & $6.8 \pm 3.8$ & $0.511 \dagger$ \\
\hline \multirow[t]{2}{*}{ Marital Status ${ }^{\mathrm{a}}$} & Single & $15(65.2 \%)$ & $12(50 \%)$ & \multirow[t]{2}{*}{$(p=0.292) \dagger$} \\
\hline & Married & $8(34.8 \%)$ & $12(50 \%)$ & \\
\hline \multicolumn{2}{|c|}{ History of RTC $^{\mathrm{c}}$ during past year ${ }^{\mathrm{a}}$} & $7(30.4 \%)$ & $4(16.7 \%)$ & $0.265 \$$ \\
\hline \multicolumn{2}{|c|}{ Sleep duration during last 24 hours $^{\mathrm{a}}$} & $8.7 \pm 2.1$ & $6.6 \pm 1.7$ & $0.001 *$ \\
\hline \multirow[t]{4}{*}{ Circadian rhythm } & Flexible & $6(26.1 \%)$ & $1(4.2 \%)$ & \multirow[t]{2}{*}{$0.048 \S$} \\
\hline & Rigid & $17(73.9 \%)$ & $23(98.5 \%)$ & \\
\hline & Languid & $4(17.4 \%)$ & $3(12.5 \%)$ & \multirow[t]{2}{*}{$0.701 \S$} \\
\hline & Vigorous & $19(82.6 \%)$ & $21(87.5 \%)$ & \\
\hline \multirow[t]{2}{*}{ Fatigue score ${ }^{b}$} & Before shift & $1.9 \pm 1.4$ & $1.6 \pm 1.2$ & $0.647 *$ \\
\hline & After shift & $3.3 \pm 2.3$ & $2.6 \pm 1.9$ & $0.371 *$ \\
\hline \multirow[t]{2}{*}{ Sleepiness score ${ }^{\mathrm{b}}$} & Before shift & $1.7 \pm 0.5$ & $2 \pm 0.4$ & $0.014^{*}$ \\
\hline & After shift & $3.1 \pm 1.6$ & $2.4 \pm 0.9$ & $0.121^{*}$ \\
\hline
\end{tabular}

a: n (\%), b: Mean \pm SD, c: Road traffic collision, d: Test for difference between pre-test and post-test; *MannWhitney U test, $\dagger$ t- test, $\ddagger$ Chi-square test, §Fisher's exact test 
History of RTC during the past year was reported in $30.4 \%$ of the night shift nurses and $16.7 \%$ of the day shift nurses. Score differences of sleepiness and fatigue pre- and post-shift were obtained. Night shift nurses, even with a 3-hour nap, reported significantly more sleepiness than day shift nurses (Mann-Whitney U statistics=155, $p=0.007$ ). However, score differences of fatigue pre- and post-shift were not statistically significant between night and day shift nurses (Mann-Whitney $U$ statistics $=264.5, p=0.807$ ). Table 2 shows the univariable analysis. The difference between the scores at the beginning and the end of the shift did not show any significant relationship with the shift in tests. In multiple regression analysis, by controlling the effect of potential confounders, we observed an association between shiftwork and the "median reaction time score" in the DT test, as well as the "scores based on viewing times" in the LVT test. Day shift working nurses showed more decrease in the "median reaction time score" at the end of the shift (compared to the beginning of the shift) than night shift working nurses ( $p=0.045$ ) (Table 3). Moreover, the "scores based on viewing times" at the end of the shift showed an increase in day shift working nurses, that was more than night shift working group $(\mathrm{p}=0.005)$. However, the differences of ATAVT and ZBA test scores at the end of the shift compared to the beginning of the shift, did not have any statistically significant association with shift type in regression analysis. Table 4 presents the power of multiple regression analysis for detecting a relationship of $5 \%, 10 \%$, and $15 \%$ with shiftwork.

Table 2. Univariate analysis of association between night- work and psychomotor driving performance scores

\begin{tabular}{|l|l|l|l|l|l|}
\hline Test & Variable & Unit & \multicolumn{2}{|l|}{$\begin{array}{l}\text { Score difference (After-Before shift) } \\
\text { Mean } \pm \text { SD }\end{array}$} & $\begin{array}{l}\text { p- } \\
\text { value }\end{array}$ \\
\cline { 4 - 6 } & & Day shift & Night shift & \\
\hline \multirow{2}{*}{$\begin{array}{l}\text { ATAVT (perceptual } \\
\text { speed) }\end{array}$} & Overview & - & $0.75 \pm 3.77$ & $0.30 \pm 3.28$ & 0.67 \\
\hline $\begin{array}{l}\text { DT (Choice reaction } \\
\text { time) }\end{array}$ & Incorrect response & Number & $2.0 \pm 7.26$ & $0.13 \pm 3.66$ & 0.27 \\
\cline { 2 - 6 } & Omitted response & Number & $-1.00 \pm 8.68$ & $-2.52 \pm 5.62$ & 0.48 \\
\cline { 2 - 5 } & Median Reaction time & Second & $-0.02 \pm 0.03$ & $0.00 \pm 0.03$ & 0.12 \\
\hline $\begin{array}{l}\text { LVT (Visual } \\
\text { Orientation) }\end{array}$ & Score (based on viewing times) & - & $0.79 \pm 2.04$ & $0.00 \pm 2.39$ & 0.23 \\
\hline $\begin{array}{l}\text { ZBA (Time } \\
\text { anticipation) }\end{array}$ & $\begin{array}{l}\text { Median deviation time SQRT } \\
\text { transformed }\end{array}$ & Second & $-0.05 \pm 0.23$ & $-0.07 \pm 0.24$ & 0.88 \\
\hline
\end{tabular}

Table 3. Multiple regression analysis of significant association of the psychomotor driving tests with night shift work among nurses

\begin{tabular}{|l|l|l|l|l|}
\hline Tests & Dependent variables & Coefficient & $0.95 \%$ CI & p-value \\
\hline DT Choice reaction time) & Median Reaction Time & -0.019 & $-0.037,0.000$ & $0.045^{*}$ \\
\hline LVT (Visual Orientation) & Score (based on viewing time) & -1.698 & $-2.860,-0.536$ & $0.005^{*}$ \\
& & & & \\
\hline
\end{tabular}

CI: Confidence interval; *Significant at 0.05 level

Table 4. The power of the multiple linear regression analysis to detect an association between night-work and studies variables, adjusted for potential confounders

\begin{tabular}{|l|l|l|l|l|}
\hline Test & Variables & $\begin{array}{l}\text { Power for 5\% } \\
\text { improvement in the } \\
\text { model R }\end{array}$ & $\begin{array}{l}\text { Power for 10\% } \\
\text { improvement in } \\
\text { the model R }\end{array}$ & $\begin{array}{l}\text { Power for 15\% } \\
\text { improvement in } \\
\text { the model } \mathrm{R}^{2}\end{array}$ \\
\hline ATAVT & Overview & $40.7 \%$ & $71.5 \%$ & $89.4 \%$ \\
\hline DT & Incorrect response & $90.3 \%$ & $99.9 \%$ & $>99.9 \%$ \\
\cline { 2 - 5 } & Omitted response & $62.6 \%$ & $93.0 \%$ & $99.5 \%$ \\
\cline { 2 - 5 } & Median Reaction time* & $99.7 \%$ & $>99.9 \%$ & $>99.9 \%$ \\
\hline LVT & Score (based on viewing time)* & $82.8 \%$ & $99.9 \%$ & $>99.9 \%$ \\
\hline ZBA & $\begin{array}{l}\text { Median deviation time SQRT } \\
\text { transformed }\end{array}$ & $60.3 \%$ & $91.5 \%$ & $99.2 \%$ \\
\hline
\end{tabular}

*A statistically significant difference was observed in night shift participants compared to day shift

\section{Discussion}

In the present study, we compared the effect of night and day shift work on the psychomotor driving performance of the nurses after shifts, including choice reaction time, perceptual speed, visual orientation and time anticipation. The results revealed increased sleepiness and choice reaction time and decreased visual orientation ability after the night 
shift among the nurses. Some studies in agreement with our study indicated an increase in sleepiness, and as a result, a decrease in psychomotor performance associated with the duration of the shift work among health care and professional drivers (25). In line with our study, several studies have shown that sleepy drivers have slower reaction times $(26,27)$, which make it hard to identify the dangers and react to them rapidly and properly (28). A research by Vetter et al. indicated an increase of median reaction time among night shift workers (29). In our study, in choice reaction time test, median reaction time revealed a significant direct association with the night shift, indicating that the reactive stress tolerance becomes worse after the night shift compared to the day shift. However, no significant association was found between the type of shift and changes in the scores in other components of this test such as correct response, incorrect response, and omitted response after the shift, compared to before the shift. A study done by Vorster $\mathrm{P}$ et al. indicated that participants who balance their reaction time with accuracy are less likely to make incorrect responses and make more correct responses in sufficient time. Fast reaction times and low accuracy also lead to more accidents. Intermediate reaction time and intermediate accuracy is required for fewer accidents in real situations (30). Also inconsistent with our study, another research indicated choice reaction time improved in both night, morning and late afternoon shift groups at the end of the shift. The authors believed that learning effects and voluntary choice of night shift were possible reasons for these results among night shift workers (31). Choice reaction time test includes multiple stimuli and multiple responses, so attention requirements are more, and it is highly crucial in driving vehicles when unpredicted traffic signals present (32). A study by Durić P et al. indicated that drivers who were involved in traffic collisions showed longer choice reaction time (33). Also, in our study, visual orientation that means accuracy, and speed in gaining an overview, revealed significant associations with the night shift. While driving, the orienting operation is essential to concentrate on locations of important information such as when the traffic light turns from yellow to red. Also, in an unpredictable situation, for example, when a driver appears from the back of a parked car, the orienting ability is essential for shifting the attentional focus to another location in the field of vision and respond to the appearance of a new object, i.e., the driver (34). On the other hand, in our study, changes in the scores of observational ability such as perceptual speed, and time anticipation, did not show any significant association with a 12-hour night shift with a 3- hour nap. It is likely that the 3-hour nap time in our study is an effective factor in this regard. Moreover, research has shown that increasing working hours from 6 to 9 hours increased the risk of sleepiness in 51\% of the participants. While each hour of the main sleep reduced the drowsiness by $15 \%$ (35). Based on the power of the present study in Table 3, there was no significant difference between the night and day shift nurses in the 2 above-mentioned tests. Palermo et al. surveyed the association between length of nap (up to 2 hours, 2- 3 hours, and 3 hours or more) during the night shift and the performance after work among 1,940 nurses of 18 public hospitals in Brazil. The results revealed that the association was only significant for the group who napped 2 to 3 hours during the night shift (36). The decrease in performance after a night shift was not solely attributed to the night shift per se. Instead, the longer length of the night shift, compared to the day shift, might have been due to a secondary effect on the psychomotor abilities of driving. Night shift nurses with a 3-hour nap worked 9 hours, and day shift nurses worked 7 hours. Furthermore, according to several studies, extended nursing shift causes poor quality of sleep (25), and napping during the night shift has a poorer quality compared to normal nocturnal sleep (37). A study by Ruggiero et al. revealed that $42 \%$ to $50 \%$ of the participants were not able to sleep during their nap opportunity in the night shift because of the noisy environment (4). The results may also be affected by the time-on-task effect. Another explanation is that nurses may be suffering from the effects of sleep inertia. Studies have also shown that night work adversely affects psychomotor performance as a result of the struggle between night work programs and circadian rhythm (38). Moreover, as shift workers regularly decide to switch back to night sleep and daytime activities on their days off, their adjusted sleepwake schedule is not retained long enough to be adequately adapted (39).

\section{Strengths and Limitations}

In this study, most of the variables that could affect the test results were self-matched. Therefore, the internal validity of the study was verified. The results are roughly generalizable to female night shift working health professionals, as most of them are nurses. If the personality traits of the nurses had been assessed as potential intervening factors and circadian rhythm (flexible/rigid) and amplitude (languid/vigorous) had been equally distributed between the 2 groups, it would have added more validity to the study. While all participants were asked to abstain from taking coffee and anti-sleeping pills in the past 24 hours prior to the study, we were not able to document the adherence to this request.

\section{Conclusions}

It appears that the 12-hour night shift with a 3-hour nap along with subjective sleepiness after shift was one of the findings of the present study. This study found that choice reaction time and visual orientation even with a 3 -hour 
nap, were impaired significantly after the night shift to a point, where it was unsafe for them to drive home after a night shift. Moreover, in our study, no significant difference was found between night and day shift nurses in the perceptual speed, and time anticipation ability of driving after shift.

\section{Acknowledgments:}

This study was sponsored by Sina Trauma and Surgery Research Center (NO.30427), affiliated to Tehran University of Medical Sciences. The authors wish to acknowledge the participation of the nurses of Sina hospital in this study.

\section{Conflict of Interest:}

There is no conflict of interest to be declared.

\section{Authors' contributions:}

Soheil Saadat; Research design, supervision of the study, data analysis, advised and revised the study draft. Farideh Sadeghian; literature search, data collection, prepared the first draft of the manuscript and revised: Mojgan Karbakhsh, Mahnaz saremi, Iraj Alimohammadi, Hassan Ashayeri, Reza Rostami; Advised and revised the study draft. Mahsa Fayaz; data analysis and revised the study draft.

\section{References:}

1) Bazeli J, Aryankhesal A, Khorasani-Zavareh D. Exploring the perception of aid organizations' staff about factors affecting management of mass casualty traffic incidents in Iran: a grounded theory study. Electron Physician. 2017; 9(7): 4773-9. doi: 10.19082/4773. PMID: 28894534, PMCID: PMC5586992.

2) Gonçalves M, Amici R, Lucas R, Åkerstedt T, Cirignotta F, Horne J, et al. Sleepiness at the wheel across Europe: a survey of 19 countries. Journal of sleep research. 2015; 24: 242-53. doi: 10.1111/jsr.12267. PMID: 25581328.

3) Mathis J. Driving ability and daytime sleepiness. Therapeutische Umschau Revue therapeutique. 2011; 68(5): 253-9. doi: 10.1024/0040-5930/a000160. PMID: 21506087.

4) Hilditch CJ, Dorrian J, Centofanti SA, Van Dongen H, Banks S. Sleep inertia associated with a 10-min nap before the commute home following a night shift: A laboratory simulation study. Accident Analysis \& Prevention. 2017; 99(Pt B): 411-5.

5) Boivin D, Boudreau P. Impacts of shift work on sleep and circadian rhythms. Pathologie Biologie. 2014; 62(5): 292-301. doi: 10.1016/j.patbio.2014.08.001. PMID: 25246026.

6) Scott LD, Hwang WT, Rogers AE, Nysse T, Dean GE, Dinges DF. The relationship between nurse work schedules, sleep duration, and drowsy driving. Sleep. 2007; 30(12): 1801-7. doi: 10.1093/sleep/30.12.1801. PMID: 18246989, PMCID: PMC2276124.

7) Ftouni S, Sletten TL, Howard M, Anderson C, Lenné MG, Lockley SW, et al. Objective and subjective measures of sleepiness, and their associations with on - road driving events in shift workers. Journal of sleep research. 2013; 22(1): 58-69. doi: 10.1111/j.1365-2869.2012.01038.x. PMID: 22861524.

8) Novak RD, Auvil-Novak SE. Focus group evaluation of night nurse shiftwork difficulties and coping strategies. Chronobiology international. 1996; 13(6): 457-63. doi: 10.3109/07420529609020916. PMID: 8974191.

9) Bjorvatn B, Stangenes K, Oyane N, Forberg K, Lowden A, Holsten F, et al. Subjective and objective measures of adaptation and readaptation to night work on an oil rig in the North Sea. Sleep. 2006; 29(6): 821-9. doi: 10.1093/sleep/29.6.821. PMID: 16796221.

10) He J, Choi W, Yang Y, Lu J, Wu X, Peng K. Detection of driver drowsiness using wearable devices: a feasibility study of the proximity sensor. Appl Ergon. 2017; 65: 473-80. doi: 10.1016/j.apergo.2017.02.016. PMID: 28420482.

11) Lee ML, Howard ME, Horrey WJ, Liang Y, Anderson C, Shreeve MS, et al. High risk of near-crash driving events following night-shift work. Proceedings of the National Academy of Sciences. 2016; 113(1): 176-81. doi: 10.1073/pnas.1510383112. PMID: 26699470, PMCID: PMC4711869.

12) Åkerstedt T, Peters B, Anund A, Kecklund G. Impaired alertness and performance driving home from the night shift: a driving simulator study. Journal of sleep research. 2005 ; 14(1): 17-20. doi: 10.1111/j.13652869.2004.00437.x. PMID: 15743329.

13) Dawson D, Reid K. Fatigue, alcohol and performance impairment. Nature. 1997; 388(6639): 235. doi: 10.1038/40775. PMID: 9230429. 
14) Stahl P, Donmez B, Jamieson GA. Anticipation in driving: The role of experience in the efficacy of preevent conflict cues. IEEE Transactions on Human-Machine Systems. 2014; 44(5): 603-13. doi: 10.1109/THMS.2014.2325558.

15) Lovato N, Lack L. The effects of napping on cognitive functioning. Progress in brain research. 2010; 185 : 155-66. doi: 10.1016/B978-0-444-53702-7.00009-9. PMID: 21075238.

16) Ruggiero JS, Redeker NS. Effects of napping on sleepiness and sleep-related performance deficits in nightshift workers: a systematic review. Biol Res Nurs. 2014; 16(2): 134-42. doi: 10.1177/1099800413476571. PMID: 23411360, PMCID: PMC4079545.

17) Dagtekin O, Gerbershagen HJ, Wagner W, Petzke F, Radbruch L, Sabatowski R. Assessing cognitive and psychomotor performance under long-term treatment with transdermal buprenorphine in chronic noncancer pain patients. Anesthesia \& Analgesia. 2007; 105(5): 1442-8. doi: 10.1213/01.ane.0000281078.65585.1e. PMID: 17959980.

18) Shmygalev S, Dagtekin O, Gerbershagen HJ, Marcus H, Jübner M, Sabatowski R, et al. Assessing cognitive and psychomotor performance in patients with fibromyalgia syndrome. Pain Ther. 2014; 3(2): 85 101. doi: 10.1007/s40122-014-0028-0. PMID: 25344449, PMCID: PMC4269614.

19) Sommer M, Herle M, Häusler J, Risser R, Schützhofer B, Chaloupka C. Cognitive and personality determinants of fitness to drive. Transportation research part F: traffic psychology and behaviour. 2008; 11(5): 362-75. doi: 10.1016/j.trf.2008.03.001.

20) Sommer M, Häusler J. Non-linear methods for the identification of drivers at risk to cause accidents. Driver behaviour and training. 2005; 2: 425-36.

21) Jafari-Roodbandi A, Hashemi-nejad N, Sadeghi M, Baneshi M, Haji-maghsoudi S, Rastegari A. Internal Consistency and Confirmatory Factor Analysis of Persian Version Circadian Type Inventory in Iranian Day Worker and Shift Worker employees, 2011-2012. Iran Occupational Health. 2013; 10(3).

22) Farvaresh E, Monazam MR, Abbassinia M, Asghari M, Sadeghi A, Mohammadian F. Investigation the relationship between sleepiness and general health of shift workers in the automobile industry. Journal of North Khorasan University of Medical Siences. 2012; 4: 221-7.

23) Javadpour F, Keshavarzi S, Choobineh A, Aghabaigi M. Validity and reliability of the Swedish Occupational Fatigue Inventory (SOFI-20) among Iranian working population. Journal of Ergonomics. 2015; 3: 50-8.

24) Di Milia L, Smith PA, Folkard S. A validation of the revised circadian type inventory in a working sample. Personality and Individual differences. 2005; 39(7): 1293-305. doi: 10.1016/j.paid.2005.04.012.

25) Geiger-Brown J, Rogers VE, Trinkoff AM, Kane RL, Bausell RB, Scharf SM. Sleep, sleepiness, fatigue, and performance of 12-hour-shift nurses. Chronobiology international. 2012; 29(2): 211-9. doi: 10.3109/07420528.2011.645752. PMID: 22324559.

26) Dinges DF. An overview of sleepiness and accidents. Journal of sleep research. 1995; 4(s2): 4-14.

27) Jackson ML, Croft RJ, Kennedy G, Owens K, Howard ME. Cognitive components of simulated driving performance: sleep loss effects and predictors. Accident Analysis \& Prevention. 2013; 50: 438-44. doi: 10.1016/j.aap.2012.05.020. PMID: 22721550.

28) Golden A, Twery M, Hunt CE. National Center on Sleep Disorders Research. Sleep Medicine. 2004; 5(1): 83-5. doi: 10.1016/j.sleep.2003.11.001.

29) Vetter C, Juda M, Roenneberg T. The influence of internal time, time awake, and sleep duration on cognitive performance in shiftworkers. Chronobiology international. 2012; 29(8): 1127-38. doi: 10.3109/07420528.2012.707999. PMID: 22888791.

30) Vorster P, Pires J, Taylor N, van Rooyen J. How to Effectively Select Candidates and Interpret Assessment Data for Safety in Leading Mines. SAIMM, AMMSA and SACMA. 2011.

31) Petru R, Wittmann M, Nowak D, Birkholz B, Angerer P. Effects of working permanent night shifts and two shifts on cognitive and psychomotor performance. Int Arch Occup Environ Health. 2005; 78(2): 109-16. doi: 10.1007/s00420-004-0585-3. PMID: 15726392.

32) Henry FM, Rogers DE. Increased response latency for complicated movements and a "memory drum" theory of neuromotor reaction. American Association for Health, Physical Education and Recreation. 1960; 31(3): 448-58. doi: 10.1080/10671188.1960.10762052.

33) Durić P, Filipović D. Reaction time of drivers who caused road traffic accidents. Med Pregl. 2009; 62(3-4): 114-9. doi: 10.2298/MPNS0904114D. PMID: 19623838.

34) Trick LM, Enns JT, Mills J, Vavrik J. Paying attention behind the wheel: A framework for studying the role of attention in driving. Theoretical Issues in Ergonomics Science. 2004; 5(5): 385-424. doi: $10.1080 / 14639220412331298938$. 
35) Härmä M, Sallinen M, Ranta R, Mutanen P, Müller K. The effect of an irregular shift system on sleepiness at work in train drivers and railway traffic controllers. Journal of sleep research. 2002; 11(2): 141-51. doi: 10.1046/j.1365-2869.2002.00294.x. PMID: 12028479.

36) Palermo TA, Rotenberg L, Zeitoune RC, Silva-Costa A, Souto EP, Griep RH. Napping during the night shift and recovery after work among hospital nurses. Rev Lat Am Enfermagem. 2015; 23(1): 114-21. doi: 10.1590/0104-1169.0147.2532. PMID: 25806639 PMCID: PMC4376039.

37) Borges FND, Fischer FM, Rotenberg L, Soares NS, Fonseca MB, Smolensky MH, et al. Effects of naps at work on the sleepiness of 12-hour night shift nursing personnel. Sleep Science. 2009; 2(1): 24-9.

38) Lamond N, Dorrian J, Roach GD, McCulloch K, Holmes A, Burgess H, et al. The impact of a week of simulated night work on sleep, circadian phase, and performance. Occupational and environmental medicine. 2003; 60(11): e13-e.

39) Akerstedt $T$, Landström U. Work place countermeasures of night shift fatigue. International journal of industrial ergonomics. 1998; 21(3-4): 167-78. doi: 10.1016/S0169-8141(97)00045-0. 